\title{
Assessing the Relationship between Social Vulnerability, Social Capital, and Housing Resilience
}

\author{
Sebastian Rowan *(1) and Kyle Kwiatkowski (i) \\ Department of Civil and Environmental Engineering, University of New Hampshire, Durham, NH 03824, USA; \\ kyle.kwiatkowski@unh.edu \\ * Correspondence: sbs44@wildcats.unh.edu
}

Received: 27 August 2020; Accepted: 17 September 2020; Published: 18 September 2020

check for updates

\begin{abstract}
Social vulnerability and social capital have been shown to influence how severely communities are impacted by natural hazards and how quickly they recover. Indices exist to quantify these factors using publicly available data; however, more empirical research is needed to validate these indices and support their use in pre-disaster planning and decision making. Using data from the Federal Emergency Management Agency and data gathered through imagery analysis in Google Earth, this study evaluates the effectiveness of two indices of social vulnerability and social capital to predict housing impacts and rates of recovery in Florida and Puerto Rico following Hurricanes Irma and Maria in 2017. We found the social vulnerability index to be statistically significant in explaining the variation of housing impacts in both case studies, with varying results for the sub-indices of social vulnerability. Results for the social capital index were mixed between the case studies, and we found no statistically significant relationship between any of the indices and rates of housing recovery. Our results show that indices such as these can be useful, with an awareness of limitations, for researchers and emergency practitioners, and additional empirical analysis is needed to more fully support their efficacy for resilience assessment.
\end{abstract}

Keywords: social vulnerability; social capital; index; disaster; housing; recovery; resilience

\section{Introduction}

Each year, disasters affect millions of people and cause billions of dollars in damages worldwide [1]. Between 2008 and 2018, 663 events were classified as disasters by the Centre for Research on the Epidemiology of Disasters (CRED). Floods or storms caused 476 (72\%), which accounted for over $65 \%$ of disaster-related economic losses. As the frequency and intensity of extreme weather events are expected to increase due to climate change [2,3], there is a growing need to understand the factors that affect resilience to these events, and to incorporate these factors into planning and decision-making tools for emergency management, recovery, and risk reduction.

One such tool is the Center for Disease Control and Prevention's (CDC's) Social Vulnerability Index (SVI) database [4]. This tool uses socioeconomic and demographic data from the U.S. Census to identify areas at higher risk from natural hazards and is used in planning hazard mitigation efforts and coordinating emergency response operations [5]. The SVI is intended as a tool for practitioners at all stages of the disaster management cycle, and, thus, should be useful to decision-makers coordinating limited resources in the immediate aftermath of a large disaster event. One such consideration is the deployment of emergency shelter and assistance for the repair of damaged housing. In theory, areas with higher levels of social vulnerability will experience greater levels of damage to housing, and practitioners may prioritize response efforts in these areas. Despite its widespread use, there is little empirical research validating the SVI with data from specific natural hazard events. 
Social capital is another factor that has been shown to be important to resilience. Unlike social vulnerability, there has not been much work to develop appropriate indicator variables and combine them into a tool for resilience assessment. However, a recent study [6] develops a social capital index (SoCI) intended for resilience assessment and disaster risk management, which uses publicly available data to calculate measures of social capital in U.S. counties.

More research is needed to assess the validity of the selected indicators at all phases of the disaster cycle, to ensure that tools such as the SVI and SoCI are accurate and reliable. This study uses housing damage assessments in Florida and Puerto Rico from Hurricanes Irma and Maria to assess the ability of the SVI and SoCI to predict hazard impacts at the county scale. Using aerial imagery, we also measure housing recovery in 36 census tracts in Puerto Rico and use this data to evaluate how well the SVI and SoCI explain variability in recovery outcomes.

\section{Background}

The natural hazards literature contains many definitions of vulnerability, which can be generalized as "the potential for a loss" [7]. Throughout much of the 20th century, hazards research viewed vulnerability as a purely physical phenomenon. It was not until the later part of the century that researchers began to recognize that social and economic factors contribute to vulnerability, as well $[8,9]$. The hazards of place model, developed by Susan Cutter, groups community vulnerability into biophysical and social vulnerability. Biophysical vulnerability arises from a community's geographic context and the probability that it will be exposed to a hazard. Social vulnerability arises from the community's "social fabric", which includes socioeconomic and demographic characteristics that affect community response, coping, and recovery from a hazard event [7]. Several indices exist using census data to measure vulnerable populations and create consistent metrics of social vulnerability with which to compare communities across a broader geographic context. Emergency practitioners use these indices for disaster planning, response, and recovery operations. Hazards researchers also use them to improve the understanding of social vulnerability and how different communities experience disasters [10].

Cutter et al. [11] developed an index of social vulnerability, known as the SoVI, which uses 11 variables from the U.S. Census to rank the social vulnerability of U.S. counties. Validation of the SoVI compared the number of presidential disaster declarations by county in the 1990s and found no significant difference between the number of declarations in counties with high SoVI scores and those with low scores. This validation method may be misleading, however, as a presidential disaster declaration does not imply a specific minimum level of impact, and there may be political pressure for the president to make such a declaration [12,13]. Sherrieb et al. [14] used the SoVI to develop a community resilience index to show that counties in Mississippi with higher levels of social vulnerability scored lower in measures of resilience, however, the community resilience index was not validated with disaster impact or recovery data. A study by Flannagan et al. [9] developed a similar social vulnerability index, dubbed the SVI, which measures social vulnerability across four distinct themes. In this study, the authors used data from New Orleans following Hurricane Katrina to validate the index. This analysis found that drowning victims were disproportionately elderly, and areas with high levels of social vulnerability were less likely to have returned to pre-Katrina population levels than areas with low levels of social vulnerability. The SVI methodology developed in the Flannagan study is used by the CDC to develop its SVI database, which is now widely used by emergency managers [5].

The SVI is calculated using 15 indicators from the U.S. Census Bureau's American Community Survey. These indicators are classified into four themes representing different aspects of social vulnerability: (1) socioeconomic status, (2) household composition and disability, (3) minority status and language, and (4) housing and transportation. The socioeconomic status theme measures per-capita income, poverty, unemployment, and the percentage of the population without a high school diploma. Communities that rank high in this theme are less likely to have resources available to prepare for and recover from a disaster, and any losses experienced from a hazard event are more likely to represent a 
greater proportion of overall household assets [9]. The household composition and disability theme measures the percentage of the population age 65 and older, percentage of the population age 17 and younger, percentage of the population age 5 and older with a disability, and the percentage of single-parent households. More vulnerable communities, as ranked by this theme, are more likely to require financial support or other assistance during a disaster [9]. Minority status and language measures the percentage of the population that is not non-Hispanic-white, and the percentage of the population that does not speak English at least well. Discrimination against racial and ethnic minorities has resulted in less economic development in these communities, and hazard mitigation projects which are selected based on economic benefit are more likely to go to more developed areas, leaving minority communities more vulnerable. Additionally, people with limited English proficiency may find it difficult to receive hazard alerts or to communicate with government agencies and aid organizations for assistance [9]. The housing and transportation theme measures the percentage of housing units classified as multi-unit, percentage of housing units that are mobile homes, the percentage of housing units classified as crowded, percentage of the population living in group quarters, and the percentage of households with no vehicle available. These factors may affect evacuation capabilities, and structures in these categories are less likely to be able to withstand the impacts of severe hazards such as hurricanes or earthquakes [9].

Social capital is another factor that has been shown to be important in community disaster recovery [15-17]. Social capital is defined as "social networks and the norms of reciprocity and trustworthiness that arise from them" [18]. Communities with strong social networks are more likely to work together during the recovery process and are more likely to have connections with government agencies and aid organizations that can provide resources for recovery [15]. Social capital can also reduce vulnerability as strong social networks can facilitate the sharing of hazard warnings allowing people more time to prepare or make the decision to evacuate [19]. Communities with higher levels of social capital may also be more successful in coordinating and sharing resources in preparing for disasters (e.g., labor, emergency supplies, boarding up windows and doors) [19]. Although there is not yet widespread agreement on how best to operationalize social capital, researchers have recognized the need to develop quantitative measures that can be used by emergency managers and disaster researchers $[10,15,17,20]$.

There have been a few attempts to develop indices of social capital. In, Bowling Alone: The Collapse and Revival of the American Community [18], Robert Putnam develops a state-level index of social capital comprised of measures of civic and political participation. Using this index, Putnam found that high levels of social capital were associated with several positive community characteristics, including better child welfare and educational performance, lower murder and mortality rates, and greater tolerance for gender/racial equality and civil liberties [18]. Rupasingha et al. [21] developed a county-level index of social capital and used this to identify socioeconomic and demographic indicators of social capital production. These indicators can be easily calculated using publicly available data from the U.S. Census Bureau, allowing for a consistent approach to measuring social capital across U.S. counties. Building on this work, Kyne and Aldrich [6] developed an index of social capital (SoCI) to assess community disaster resilience. This index was validated using data from historical disaster impacts in the United States and results showed that higher levels of social capital were associated with fewer fatalities, but greater levels of damage. This damage assessment included commercial property losses, which may have affected this finding.

The SoCI measures social capital using 19 indicators calculated with data from the U.S. Census Bureau and the Environmental Systems Research Institute (ESRI). These variables represent three types of social capital: bonding, bridging, and linking. Bonding social capital is formed through strong connections between family members, close friends, and neighbors [18]. These types of relationships tend to exhibit a high level of "homophily", or similarity in terms of race, ethnicity, or language. The indicators of bonding social capital used in the SoCI are direct measures of homophily within the study area, which are used as a proxy for bonding social capital. Weaker ties between individuals 
from different groups serve to connect groups that may not otherwise interact [18]. These types of relationships are more likely to be formed in communities where there are more opportunities for people from different groups to interact [19]. Bridging indicators in the SoCI measure the number of organizations within a county, such as churches or charitable organizations, that may facilitate these types of interactions. Linking social capital is characterized by vertical relationships across a social hierarchy, such as between residents and government officials [15]. The SoCI captures linking social capital based on the percentage of the labor force working for government agencies, the percentage of the population who are eligible to vote, and the percentage of the population that has participated in political activities.

Validation using empirical research is needed to ensure indicators of social vulnerability and social capital are appropriately and effectively put into practice. Using case studies in Florida and Puerto Rico from the 2017 U.S. hurricane season, this study assesses the ability of indicators of social vulnerability and social capital to predict impacts to and recovery outcomes of housing infrastructure.

Research questions:

1. How well do the SVI and SoCI (including their sub-indices) explain variance in housing damage from a hurricane?

2. How well do these indices explain variance in rates of housing recovery?

\section{Study Context}

The study area for this project is all counties in Florida and Puerto Rico that were declared eligible for Individual Assistance by the Federal Emergency Management Agency (FEMA) due to Hurricanes Irma and Maria, shown in Figure 1.

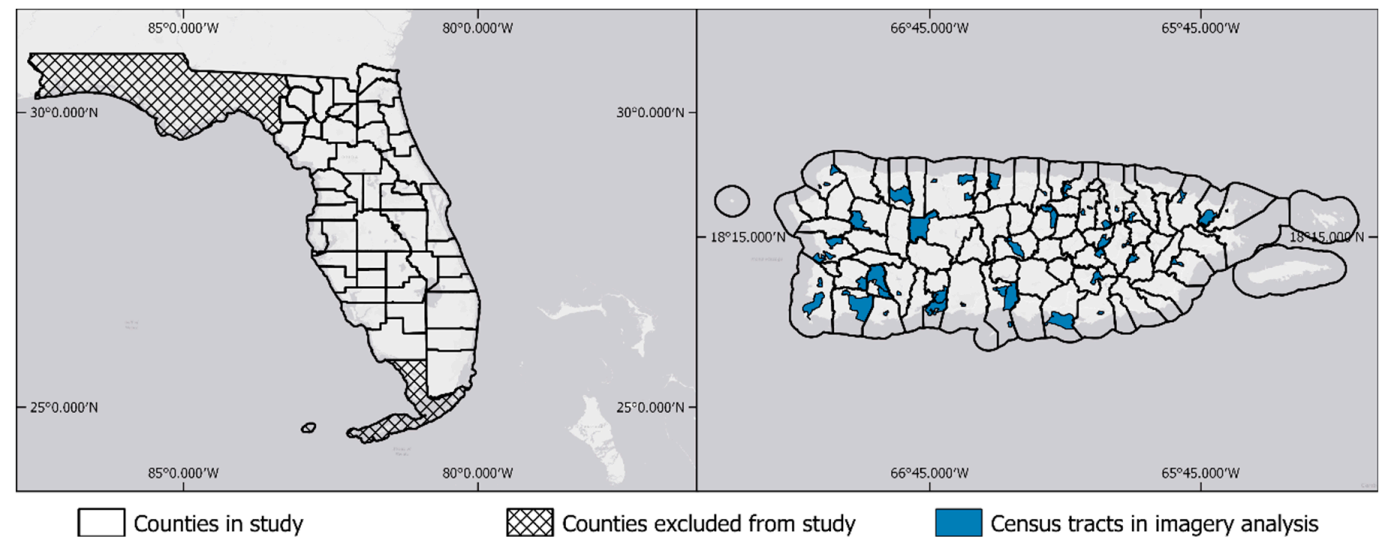

Figure 1. Counties in Florida and Puerto Rico included in this study, and census tracts in Puerto Rico included in the recovery assessment.

\subsection{Florida-Hurricane Irma}

Hurricane Irma made landfall in the Florida Keys as a category four hurricane on 10 September 2017, and moved north up the Florida peninsula, decreasing in intensity before moving into southeastern Georgia as a tropical storm [22]. Irma is the fifth-costliest tropical cyclone to impact the United States, causing an estimated $\$ 52.5$ billion in total damages (2020 CPI-adjusted cost) [23]. Of Florida's 67 counties, 49 were designated eligible for Individual Assistance by FEMA.

Monroe County, FL, which contains the Florida Keys, was excluded from this analysis. The geography of the Florida Keys is much different from the rest of the counties in Florida, and the peak wind gust there was greater than in any other county. Per-capita housing losses were also one to two orders of magnitude higher than all other counties. Including this county in the regression analysis suggests a stronger relationship between wind speed and housing damage than is observed in the remaining counties. 


\subsection{Puerto Rico-Hurricane Maria}

Hurricane Maria made landfall in southeastern Puerto Rico on 20 September 2017, as a category four hurricane and moved diagonally across the island, reentering the Atlantic Ocean near northwestern Puerto Rico as a category three hurricane [24]. Maria is the third-costliest tropical cyclone to impact the United States, causing an estimated $\$ 94.5$ billion in total damages (2020 CPI-adjusted cost) [23]. All 78 municipios (Puerto Rico county equivalent) in Puerto Rico were designated eligible for Individual Assistance by FEMA.

\section{Methods}

The objective of this study is to evaluate the SVI and SoCI as resilience assessment tools. For a tool to be useful, it should be able to identify areas that are likely to experience greater impacts from a given hazard and have more difficulty in recovering from those impacts without additional assistance. While a specific tool may not be able to achieve both of these goals, planners and decision-makers need to know which tools to use for a given assessment. We use two case studies from the 2017 hurricane season to assess how well the SVI and SoCI explain variance in levels of housing damage in hurricane-affected counties in Florida and Puerto Rico. We also assess the ability of these indices to explain variance in rates of housing recovery in a sample set of census tracts in Puerto Rico.

\subsection{Data}

\subsubsection{Social Vulnerability Index}

The Social Vulnerability Index uses 14 variables from the U.S. Census Bureau American Community Survey to measure social vulnerability. A score ranging from 0 , or least vulnerable, to 1 , most vulnerable, is calculated for each of the SVI themes through a percentile ranking method of the underlying variables. These scores are further combined to form the overall SVI. The spatial distribution of overall social vulnerability in Florida and Puerto Rico is shown in Figure 2, colored by quartile. A full list of the variables that comprise the SVI, as well as maps of the distribution of each theme, are included in Appendix A. For a more detailed discussion of these factors and explanations of the methodology, see Flanagan et al. [9].

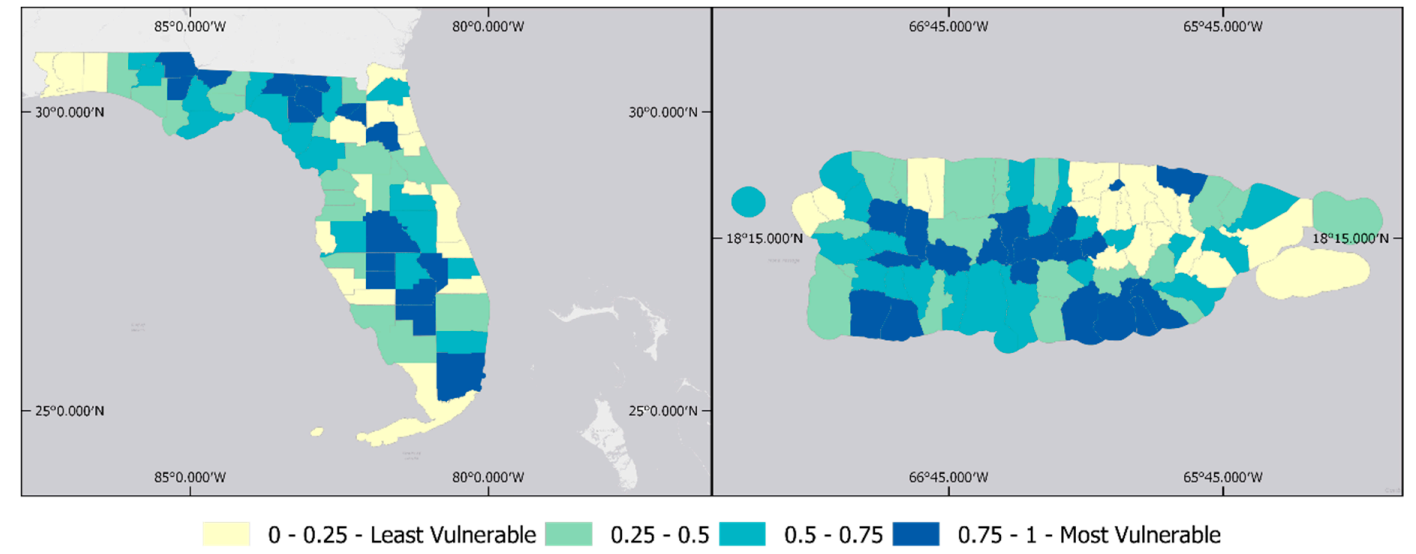

Figure 2. Distribution of social vulnerability in Florida (left) and Puerto Rico (right).

\subsubsection{Social Capital Index}

We generally follow the SoCI methodology outlined in Kyne and Aldrich [6] to develop the social capital index presented in this paper. Kyne and Aldrich use 19 indicators developed from publicly available data to operationalize social capital for counties in the contiguous United States. These indicators are not direct measurements of social capital, but they represent conditions in a community that make individuals more likely to form connections and have strong social networks 
that they can rely on to access resources when needed. We modified the calculation of some of the variables in the index to better align with the underlying theory. Some variables were modified due to data availability issues for Puerto Rico. These changes are described below. Figure 3 shows the spatial distribution of social capital in Florida and Puerto Rico, colored by quartile. The full list of variables used in the SoCI as well as maps of the distribution of bonding, bridging, and linking social capital are included in Appendix A.

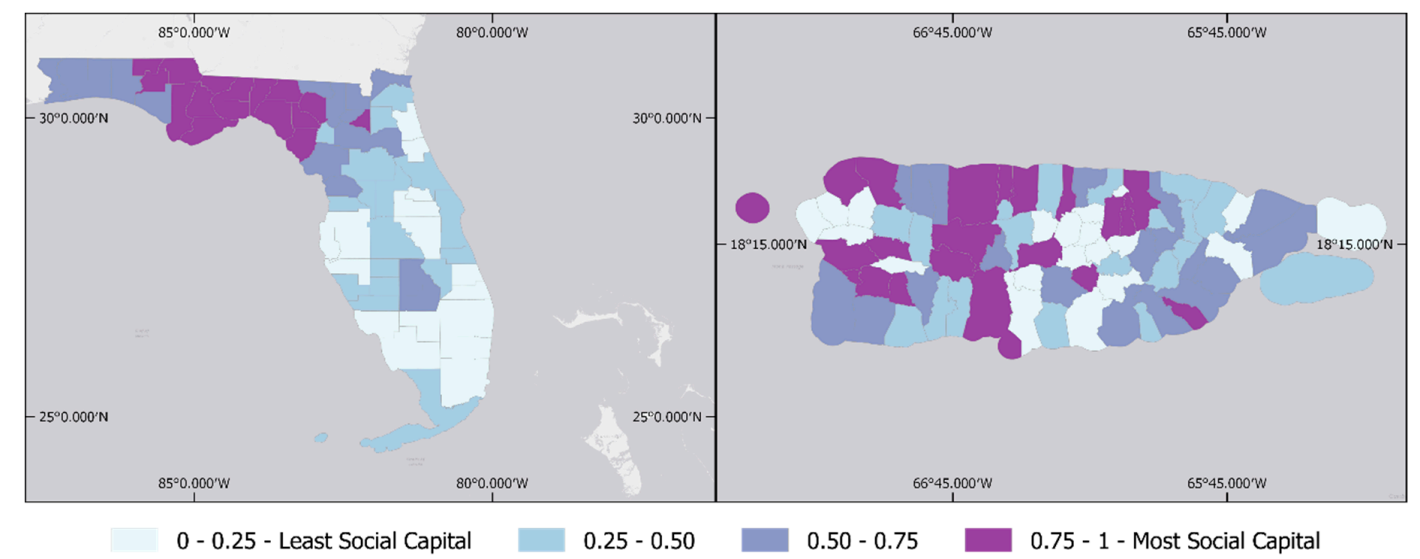

Figure 3. Distribution of social capital in Florida (left) and Puerto Rico (right).

Kyne and Aldrich calculate the educational equality indicator as the negative absolute difference between the percentage of the population with a college education and percentage of the population with less than a high school education. The purpose of this indicator is to capture differences in education levels among county populations as this is hypothesized to make individuals less likely to work together, however, the calculation for this indicator does not consider the entire population and can lead to very different communities receiving the same value. For example, consider two hypothetical counties. One county has $10 \%$ of the population with less than a high school education, $10 \%$ with a college education, and the remaining $80 \%$ with a high school education. In the second county, $50 \%$ of the population has less than a high school education, and the other $50 \%$ has a college education. With the original methodology, these counties would receive the same educational equality score. To account for this, we calculate an educational Gini coefficient for the counties to capture education equality.

A Gini coefficient, the method also used to calculate income equality in this paper, is a standard method for measuring income or wealth inequality. Thomas et al. [25] developed a methodology to calculate a Gini coefficient based on educational attainment, and we used this to calculate an educational Gini coefficient for each county in the study. Using the Gini coefficient improves the original measure as the educational Gini coefficient considers the difference in years of education completed among the population, making it a truer measure of equality rather than homogeneity. More information about how the educational Gini coefficient is calculated is included in Appendix B.

We measure employment equality, using the total population age 16 and older, as the absolute difference between the percentage employed and the percentage not employed, including people who are not employed but are seeking employment and those who are not employed and are not seeking employment. Kyne and Aldrich calculate this measure using the percentage difference between the employed and unemployed labor force, which does not include people who are not employed and are also not seeking employment. As the purpose of this measure is to capture equality among the entire population, excluding those who are not part of the labor force introduces the possibility of a misleading value for this measure if a large portion of the population is not participating in the labor force. It was important to remedy this potential source of error in this study, as the labor force participation rate in Puerto Rico is much lower than the rest of the U.S. In 2016, the overall U.S. labor force participation rate was $63.5 \%$, while the rate in Puerto Rico was just $44.8 \%$ [26]. 
To measure gender income equality, Kyne and Aldrich calculate gender income similarity using the following equation:

$$
\mathrm{GIS}=1-\left[(\mathrm{MI} / \mathrm{TI})^{2}+(\mathrm{FI} / \mathrm{TI})^{2}\right],
$$

where,

GIS $=$ Gender income similarity,

MI = Median income of non-family households for male householders,

FI = Median income of non-family households for female householders,

$\mathrm{TI}=$ Median income of non-family households for both male and female householders.

This formula assumes that both MI and FI are less than TI, and the value for GIS must fall between 0 and 1, however, given the definitions above, TI must fall between MI and FI. Therefore, with this formula, GIS will always be less than or equal to zero with no theoretical lower bound. This result can still be normalized to a range of 0 to 1 ; however, the squared terms can exaggerate or diminish small differences in median income for each gender. We believe that more research is needed to develop a robust indicator for gender income equality and have substituted this calculation for a simple ratio between the median earnings for male and female earners. We use the greater of these values as the denominator and the lesser as the numerator in the ratio, allowing the formula to be naturally bound from 0 to 1 , or completely unequal to completely equal, respectively.

Four of the SoCI variables-charitable ties, fraternal ties, union ties, and political activities-are calculated using demographic data from the Environmental Systems Research Institute (ESRI) that are not available for Puerto Rico counties. To capture these metrics for Puerto Rico, as well as to maintain consistency in measuring social capital in both case studies, these variables were replaced with data from the U.S. Census Bureau's County Business Patterns dataset. For charitable ties, union ties, and political activities, we calculated the number of each organization type per 10,000 population in each county. We have not identified an appropriate substitution to capture fraternal ties. Therefore, this variable has been removed from the index in this study.

\subsubsection{Wind Speed}

We include wind speed in this analysis to more accurately determine variance in the impact data that can be explained solely by the resilience indices. Using wind speed data for Hurricanes Irma and Maria, developed by Applied Research Associates, Inc (Albuquerque, NM, USA). [27,28], we calculated the peak wind gust for each county in the study area. Figure 4 shows the wind field from each storm color-coded according to the Safir-Simpson Hurricane Wind Scale. Although many physical factors influence hurricane damage, counties with higher peak wind gust should experience greater levels of damage. Including this data in the analysis allows us to examine how counties that experienced similar wind speeds but have different levels of social vulnerability or capital were impacted by the hurricanes.

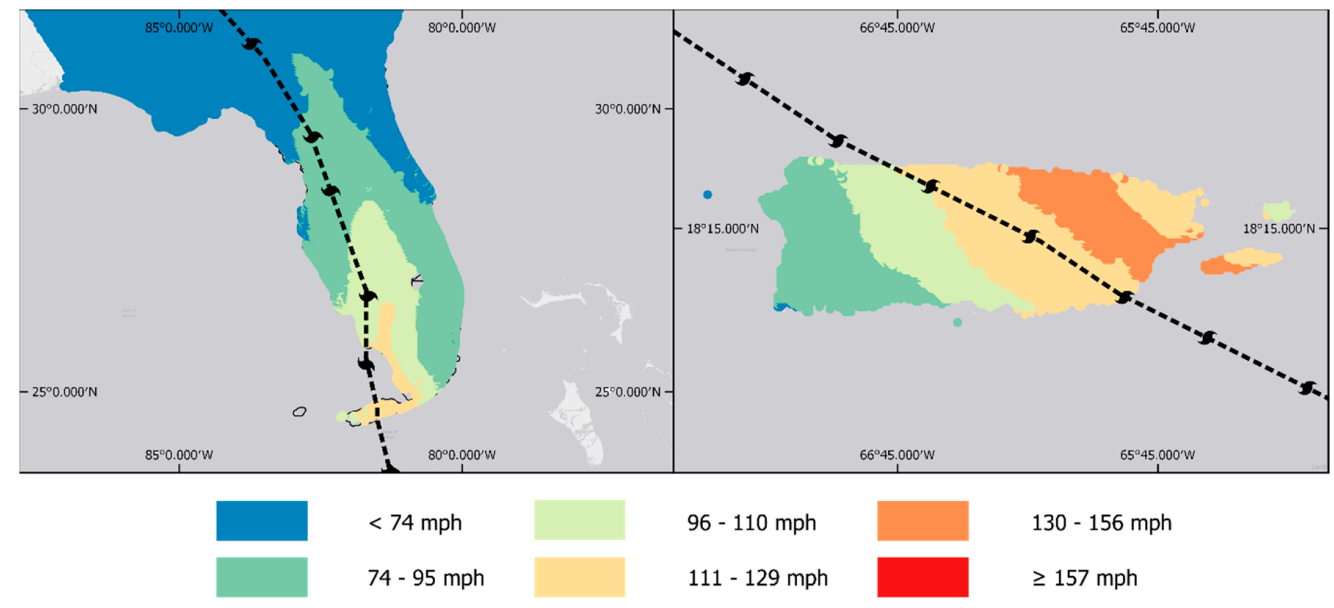

Figure 4. Path of Hurricane Irma across Florida (left) and Hurricane Maria across Puerto Rico (right), and peak wind gust from each. Colors correspond to hurricane categories in the Safir-Simpson Hurricane Wind Scale. 


\subsubsection{Housing Impacts}

The goal of this study is to determine whether the SVI and SoCI are useful predictors of housing resilience. One aspect of resilience is the ability to resist impacts from natural hazards [29]. We assess the impacts of Hurricanes Irma and Maria using data from FEMA's Individual Assistance Housing Registrants OpenFEMA dataset. (FEMA and the federal government cannot vouch for the data or analyses derived from these data after the data have been retrieved from the agency's website(s) and/or Data.gov.) This dataset contains millions of non-PII (personally identifiable information) records of registrations to FEMA's Individuals and Households Program, including registrations from Florida and Puerto Rico following Hurricanes Irma and Maria in 2017. Each record is geolocated by census block and includes the associated disaster ID number, residence type, and types and amounts of damage observed. By parsing the census block ID in each record, we aggregated the data to the county level. Impacts in each county were calculated on a per-capita basis by dividing the sum of observed real property damage in each county by the county population, shown in Figure 5.

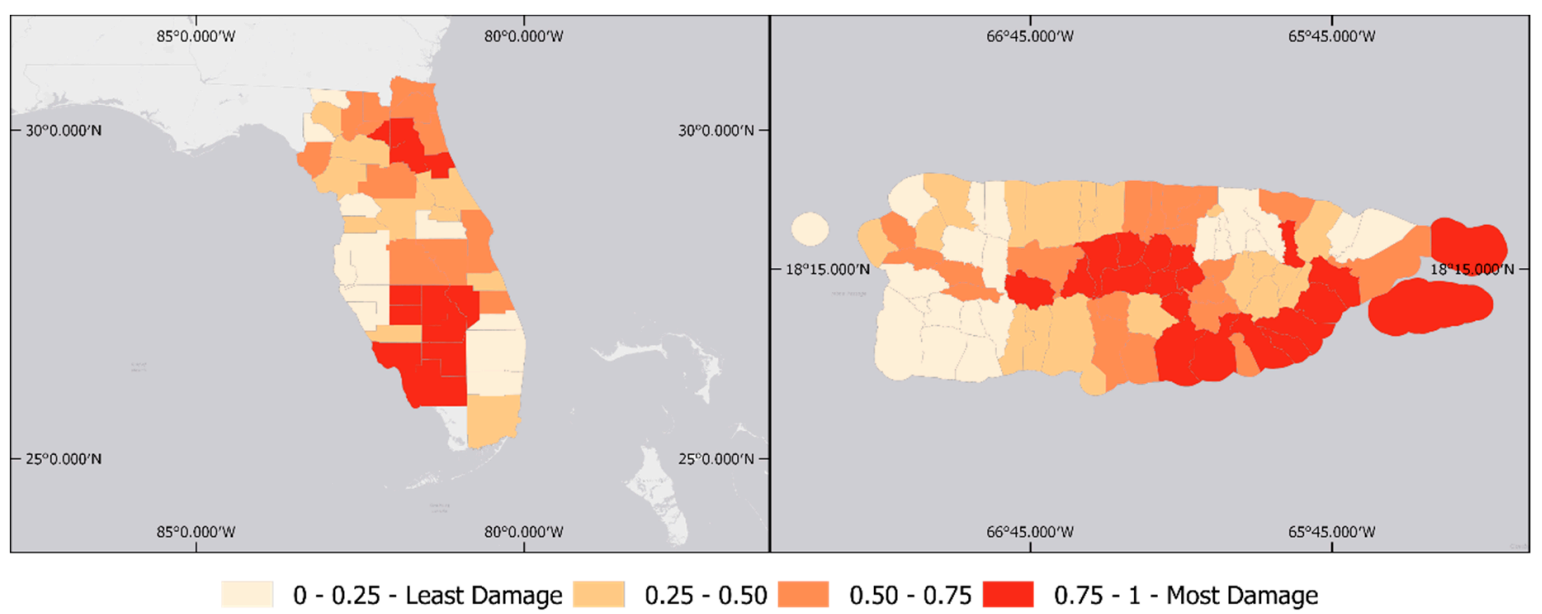

Figure 5. Percentile per-capita real property losses by county in Florida (left) and Puerto Rico (right).

\subsubsection{Housing Recovery}

Another aspect of resilience is the ability to recover from impacts over time. No publicly available datasets exist for tracking the progress of housing recovery after disasters, and tracking the recovery process typically requires repeated site visits, which can be costly and hazardous and often relies on qualitative and sometimes subjective information [30]. These data challenges make it difficult to consistently measure recovery across a large area, which is necessary to validate resilience indicators for recovery. Aerial imagery is often used during the response phase of a disaster to conduct initial damage assessments. However, it is not commonly used as a tool for long-term recovery tracking [30]. There has been work to develop systematic methodologies for tracking recovery using high-resolution satellite imagery to track indicators of recovery, such as the presence of temporary tarpaulin roofs [31,32]. These tarpaulin roofs, often called "blue roofs" are easily identified in satellite imagery due to their bright blue color, making them a useful indicator for housing recovery over time.

After Hurricane Maria, the U.S. Army Corps of Engineers (USACE) installed nearly 60,000 blue roofs on homes across Puerto Rico through their Operation Blue Roof program [33]. These roofs are meant to be temporary repairs that last one or two months until homeowners make permanent fixes; however, in Puerto Rico, many homes were still covered by blue tarps more than two years after Hurricane Maria [34]. To measure housing recovery in Puerto Rico, we used high-resolution satellite imagery available through Google Earth to count the number of structures with blue roofs in selected areas at six and 24 months after Hurricane Maria.

During the census tract selection process, we applied a stratified random sampling method to reduce potential selection biases. Census tracts were divided into strata based on quartile per-capita 
income to avoid bias based on socioeconomic status. Tracts were also divided into three groups based on their distance from the epicenter of Hurricane Maria at its nearest approach to avoid bias based on the severity of hazard exposure. Distance groups were 0 to 10 miles, 10 to 25 miles, and greater than 25 miles from the center of Hurricane Maria. Three census tracts were randomly selected from each stratum for a total of 36. Census tract boundaries were loaded into Google Earth, and a grid of 0.25 miles $\times 0.25$ miles was placed on the map to allow for a systematic scan of the census tract and to ensure that no part of the area was missed. The number of structures with blue tarp roofs was counted in each tract in the 6-month and 24-month post-event imagery in Google Earth. Housing recovery was measured as the percentage decrease in blue roofs identified between the two sets of imagery. Figure 6 shows an example of the quality of imagery available in Google Earth and the change in the number of blue roofs between the two time periods.

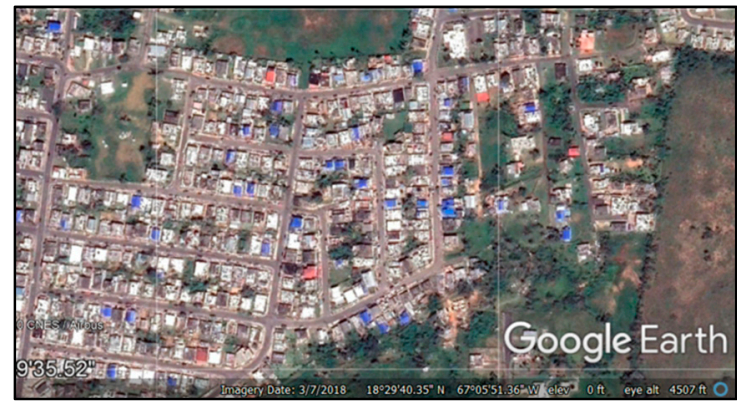

(a)

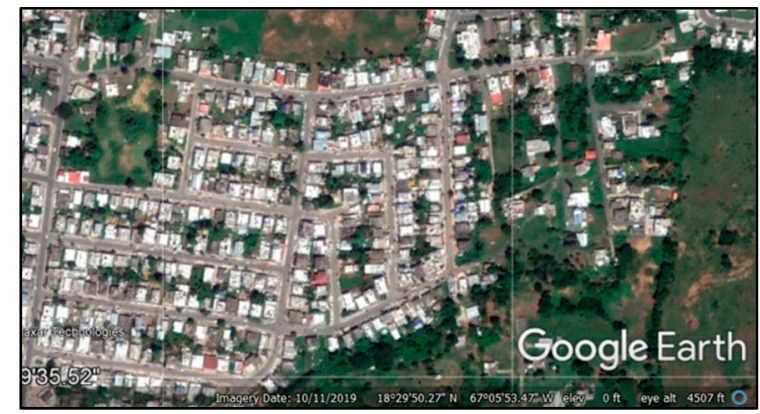

(b)

Figure 6. Google Earth aerial imagery of one location in the study area used to measure housing recovery. (a) Imagery captured 7 March 2018, showing many structures with blue tarp roofs; (b) Imagery captured 11 October 2019, showing repair of temporary blue tarp roofs.

\subsection{Impact Analysis}

To answer research question 1, we developed a series of multiple regression models that combine each of the indices with the peak wind gust data to predict per-capita housing damages in each study area. We assessed the relationship between each index and housing damages by assessing the sign on the coefficient for each index. We then compared each model to a bivariate regression model using just the peak wind gust data to predict housing damage. By comparing the amount of variance in the housing damage explained by the bivariate model to the amount explained by each multiple regression model, we determined how each index variable uniquely explained the variance. Using the change in $\mathrm{R}$-squared values for each model, we calculated an F-statistic to determine if adding the index variable to the gust-only model is a statistically significant improvement.

Other than wind speed, we did not include any additional variables to represent other physical factors that may influence housing impacts, such as housing stock characteristics. These factors are included in more robust impact assessment methodologies such as HAZUS, however, the purpose of this study is to assess how well the SVI and SoCI can serve as a proxy for these factors.

\subsection{Recovery Analysis}

To assess the relationship between the resilience indices and housing recovery, we first analyzed aerial imagery in Google Earth to develop a quantitative measure of housing recovery progress in a sample of 36 census tracts in Puerto Rico. As described above, we calculated recovery as the percentage of blue roofs repaired over a period of about 18 months. Each of the resilience indices was used as independent variables in a series of regression analyses to evaluate how well the indices explain variance in the housing recovery data.

The methodology for calculating the SVI outlined in Flanagan et al. [9] applies to both the county and census tract scale. Therefore, for the recovery analysis, we used the census tract scale SVI and SVI 
themes in the regression. Kyne and Aldrich's SoCI methodology [6] is only specified at the county scale. Additionally, census tract boundaries are drawn to group the U.S. population into relatively homogenous groups, which may affect the validity of applying the SoCI methodology at this scale, as many of the indicators are essentially measures of homogeneity. Therefore, in the regression analysis, we apply the county-level SoCI scores to the census-tracts.

\section{Results}

\subsection{Impact Analysis}

Through a series of multiple regression models, we assessed the relationship between each of the indices and per-capita housing damage. We compared each model to a bivariate regression model in which peak gust was the only independent variable, and calculated an F-statistic from the difference in explained variance (R-squared) to determine if each index was a statistically significant improvement.

In the Florida case study, the gust-only regression model explained $9.8 \%$ of the variance in housing damage, and in the Puerto Rico case study, the gust-only model explained $13.2 \%$. In both case studies, the contribution from the overall SVI was statistically significant. The overall SVI explained an additional $15.7 \%$ of the variance in the Florida analysis and $9.3 \%$ in the Puerto Rico analysis. SVI theme 1 (socioeconomic status) explains more variance in both case studies than any other SVI theme, resulting in a $21.1 \%$ increase in explained variance in the Florida analysis, and a $15.8 \%$ increase in explained variance in the Puerto Rico analysis. SVI theme 2 (household composition and disability) increased the explained variance in the Florida case study by $13.1 \%$, but this factor's contribution to the Puerto Rico case study was not statistically significant. SVI theme 3 (minority status and language) did not provide a statistically significant improvement to the model in the Florida case. However, it did significantly improve the model in the Puerto Rico case, increasing the explained variance by $13.5 \%$. SVI theme 4 (housing and transportation) increased the amount of explained variance in the Florida model by $10.5 \%$ but did not significantly improve the Puerto Rico model. The SVI and each theme were positively correlated with housing damages, except for SVI theme 4, which was negatively correlated with housing damage in the Puerto Rico case study. The full results of the analyses using the SVI and themes are shown in Table 1.

The overall SoCI was statistically significant in both case studies, however, the coefficients for this variable had opposite signs. In Florida, counties with higher SoCI scores had more damage per-capita than those with lower scores exposed to similar wind gusts. In Puerto Rico, higher SoCI scores were associated with less per-capita damages. The overall SoCI uniquely explained $12.5 \%$ and $6.4 \%$ of the variance in per-capita housing damage in Florida and Puerto Rico, respectively. The bonding SoCI had a negative coefficient in both case studies, meaning counties with higher levels of bonding social capital tended to have lower damage rates. Looking at the F-statistic, however, reveals that the bonding SoCI does not significantly increase the explained variance compared to the gust-only model in either case study. Bonding social capital explained just $0.6 \%$ of the variance in the Florida case study and $0.4 \%$ in the Puerto Rico case study. The bridging SoCI, like the overall SoCI, was positively associated with housing damages in the Florida case study, and negatively associated with damages in the Puerto Rico case study. In both case studies, the increase in explained variance due to the bridging SoCI was statistically significant, and explained more variance than any other social capital index variable. Bridging social capital explained $18.6 \%$ of the variance in the Florida case study and $17.5 \%$ of the variance in the Puerto Rico case study. The linking SoCI was positively associated with per-capita housing damages in both case studies. However, the increase in explained variance was only significant in the Puerto Rico case study. This variable explained just $1.8 \%$ of the variance in the Florida case, and it explained $16.8 \%$ of the variance in the Puerto Rico case. The full results of the analyses using the SoCI and sub-indices are shown in Table 2. 
Table 1. Multivariate regression results predicting housing damage in study counties with Social Vulnerability Index (SVI) and themes.

\begin{tabular}{|c|c|c|c|c|c|c|c|c|c|c|}
\hline \multirow[b]{2}{*}{ Factor } & \multicolumn{5}{|c|}{ Florida } & \multicolumn{5}{|c|}{ Puerto Rico } \\
\hline & F1 & F2 & F3 & F4 & F5 & P1 & $\mathbf{P} 2$ & P3 & $\mathbf{P 4}$ & P5 \\
\hline Intercept & -24.050 & -35.592 & -47.651 & -18.768 & -27.842 & -556.804 & -922.07 & -205.291 & -464.167 & -121.328 \\
\hline Peak Gust & 0.418 & 0.520 & 0.686 & 0.510 & 0.502 & 8.007 & 10.43 & 6.444 & 6.970 & 6.659 \\
\hline Overall SVI & 32.454 & & & & & 366.934 & & & & \\
\hline SVI Theme 1-Socioeconomic status & & 37.823 & & & & & 527.93 & & & \\
\hline $\begin{array}{l}\text { SVI Theme 2-Household } \\
\text { composition and disability }\end{array}$ & & & 31.073 & & & & & 31.519 & & \\
\hline $\begin{array}{c}\text { SVI Theme 3-Minority Status } \\
\text { and language }\end{array}$ & & & & 4.689 & & & & & 426.763 & \\
\hline $\begin{array}{l}\text { SVI Theme } 4 \text { - Housing and } \\
\text { transportation }\end{array}$ & & & & & 26.227 & & & & & -187.174 \\
\hline $\mathrm{N}$ (observations) & 48 & 48 & 48 & 48 & 48 & 78 & 78 & 78 & 78 & 78 \\
\hline R-squared & 0.248 & 0.302 & 0.222 & 0.094 & 0.1963 & 0.2269 & 0.2923 & 0.1343 & 0.269 & 0.1597 \\
\hline Model F-statistic & $7.411^{* *}$ & $9.735^{* * *}$ & $6.403^{* *}$ & 2.323 & $5.495^{* *}$ & $11.0^{* * *}$ & $15.49^{* * *}$ & $5.816^{* *}$ & $13.8^{* * *}$ & $7.125^{* *}$ \\
\hline$\Delta \mathrm{R}$-squared ${ }^{1}$ & 0.157 & 0.211 & 0.131 & 0.003 & 0.1053 & 0.0929 & 0.1583 & 0.0003 & 0.135 & 0.0257 \\
\hline Comparative F-statistic ${ }^{1}$ & $9.371011 * *$ & $13.57736^{* * *}$ & $7.553985^{* *}$ & 0.129139 & 5.87346 * & $9.060924 * *$ & $16.82916^{* * *}$ & 0.069308 & $13.90219^{* * *}$ & 2.338451 \\
\hline
\end{tabular}


Table 2. Multivariate regression results predicting housing damage in study counties with social capital index (SoCI) and sub-indices.

\begin{tabular}{|c|c|c|c|c|c|c|c|c|}
\hline \multirow[b]{2}{*}{ Factor } & \multicolumn{4}{|c|}{ Florida } & \multicolumn{4}{|c|}{ Puerto Rico } \\
\hline & F6 & F7 & F8 & F9 & P6 & P7 & P8 & P9 \\
\hline Intercept & -92.7777 & 5.3577 & -58.7034 & -52.7140 & -20.920 & 29.272 & 13.357 & -1048 \\
\hline Peak Gust & 1.0861 & 0.4726 & 0.8252 & 0.7974 & 5.989 & 6.631 & 6.526 & 9.037 \\
\hline Overall SoCI & 61.9914 & & & & -327.874 & & & \\
\hline Bonding SoCI & & -28.5732 & & & & -422.943 & & \\
\hline Bridging SoCI & & & 58.3416 & & & & -698.423 & \\
\hline Linking SoCI & & & & 41.586 & & & & 1503 \\
\hline N (observations) & 48 & 48 & 48 & 48 & 78 & 78 & 78 & 78 \\
\hline R-squared & 0.2234 & 0.1042 & 0.2838 & 0.1161 & 0.196 & 0.1358 & 0.307 & 0.3 \\
\hline Model F-statistic & $6.473^{* *}$ & 2.617 & $8.915^{* * *}$ & 2.954 & $9.144^{* * *}$ & $5.893^{* *}$ & $16.6^{* * *}$ & $16.07^{* * *}$ \\
\hline$\Delta \mathrm{R}$-squared ${ }^{1}$ & 0.12519 & 0.00599 & 0.18559 & 0.01789 & 0.064 & 0.0038 & 0.175 & 0.168 \\
\hline Comparative F-statistic $^{1}$ & $7.254^{* *}$ & 0.3 & $11.66^{* *}$ & 0.911 & $5.97 *$ & 0.33 & $18.94^{* * *}$ & $18^{* * *}$ \\
\hline
\end{tabular}




\subsection{Recovery Analysis}

Using aerial imagery analysis as described above, we measured housing recovery in 36 census tracts in Puerto Rico as the percentage decrease in the number of blue tarp roofs identified in each census tract over the period. We ran a series of bivariate regressions to assess how well each resilience index explains variance in this data. None of the models from this phase of the study were statistically significant. Tables 3 and 4 show the full results of these models.

Table 3. Bivariate regression results predicting housing recovery in the sample tracts.

\begin{tabular}{cccccc}
\hline & \multicolumn{5}{c}{ Puerto Rico Sample Tracts } \\
\hline Factor & P1 & P2 & P3 & P4 & P5 \\
\hline Overall SVI & 0.148 & & & & \\
SVI Theme 1-Socioeconomic status & & 0.187 & & & \\
SVI Theme 2-Household composition and disability & & & 0.033 & & \\
SVI Theme 3-Minority Status and language & & & & -0.045 & \\
SVI Theme 4-Housing and transportation & & & & & 0.155 \\
$\quad$ Intercept & 0.584 & 0.565 & 0.640 & 0.677 & 0.572 \\
N (observations) & 36 & 36 & 36 & 36 & 36 \\
R-squared & 0.057 & 0.084 & 0.002 & 0.006 & 0.084 \\
F-statistic & 2.072 & 3.107 & 0.081 & 0.193 & 3.126 \\
\hline
\end{tabular}

Table 4. Bivariate regression results predicting housing recovery in the sample tracts.

\begin{tabular}{ccccc}
\hline & \multicolumn{4}{c}{ Puerto Rico Sample Tracts } \\
\hline Factor & P6 & P7 & P8 & P9 \\
\hline Overall SoCI & 0.133 & & & \\
Bonding SoCI & & -0.686 & & \\
Bridging SoCI & & & 0.167 & \\
Linking SoCI & & & & 0.352 \\
Intercept & 0.591 & 1.071 & 0.589 & 0.532 \\
N (observations) & 36 & 36 & 36 & 36 \\
R-squared & 0.050 & 0.026 & 0.044 & 0.020 \\
F-statistic & 1.775 & 0.927 & 1.564 & 0.707 \\
\hline
\end{tabular}

\section{Discussion}

The SVI is often regarded as a valuable tool for assessing disaster resilience and guiding emergency management decisions; however, there has been little empirical research evaluating the use of the SVI as a predictive tool. The results of this study support the use of the SVI as a planning tool and highlight how the various themes impact its effectiveness. In both case studies, the overall SVI significantly improved the prediction of housing impacts in the study area over that of the peak wind gust bivariate model and was positively associated with housing damage. This means that counties with higher levels of social vulnerability experienced more per capita damage than less socially vulnerable communities exposed to a hazard of similar magnitude.

The SVI measures social vulnerability across four themes that capture different aspects of vulnerability that may be relevant in different phases of the disaster recovery process. Using the housing impact data, we also assessed the ability of each SVI theme to predict housing impacts. As expected, SVI theme 1 (socioeconomic status) significantly improved the prediction of housing damages over the gust-only model and was positively associated with housing damage. Communities that rank high in SVI theme 1 have higher rates of poverty and unemployment and lower levels of income and educational attainment. In both case studies, counties with higher SVI theme 1 scores had more per capita housing damage than similarly exposed counties with lower scores. Additionally, SVI theme 1 performed better than the overall SVI in predicting housing damages in both case studies. 
SVI theme 2 captures vulnerability based on household composition. While some of the variables in this indicator, such as the percentage of the population that is elderly or disabled, may be related to an inability to make disaster preparations, we did not identify an expected relationship between this SVI theme and housing damage. This SVI theme was a statistically significant improvement to the gust-only model in the Florida case study, performing nearly as well as the overall SVI. However, when SVI theme 2 was added to the gust-only model in the Puerto Rico case study, there was not a statistically significant improvement in the amount of explained variance in housing damage.

We expected SVI theme 3 (minority status and language) to be positively correlated with housing impacts. This outcome did not occur in the Florida case study, where adding theme 3 to the gust-only model did not significantly increase the explained variance in the model. Although the sign on the coefficient was positive, its t-statistic showed that it was not significantly different from zero. Adding theme 3 to the gust-only model in the Puerto Rico case study, though, did significantly improve the prediction of housing damage. SVI theme 3 performed better in the Puerto Rico case study than the overall SVI.

Theme 4 includes mobile homes, and we expected a higher prevalence of mobile homes to be associated with greater levels of damage. However, the impact analysis in the study calculated damages in terms of real property losses, and mobile homes are often not considered to be real property but personal property. Because the focus of this paper was housing resilience, we did not consider personal property losses in our analysis. Theme 4 also includes the prevalence of multi-unit housing, but our data only include applicant information where the applicant was the property owner. These factors likely affected how SVI theme 4 contributed to the analysis. Despite these caveats, adding theme 4 to the gust-only model in the Florida case study significantly improved the prediction of impacts, and the coefficient was positive as expected. In the Puerto Rico case study, though, theme 4 did not significantly improve the gust-only model, and the coefficient for theme 4 was negative (although not statistically significant).

We also assessed the ability of the SoCI to predict housing impacts. Although studies have shown social capital to be an important factor of disaster resilience, the social capital index developed by Kyne and Aldrich is the first attempt to develop a set of quantitative indicators of social capital for resilience assessment and planning. Our study empirically evaluates the SoCI's explanatory capability for variation in housing impacts. We expected counties with higher levels of social capital to report less per-capita damage than counties with less social capital exposed to similar wind gusts. The results of this study were mixed, however. In Puerto Rico, the overall SoCI, as well as the bonding and bridging SoCIs, were negatively associated with damages. The linking SoCI was positively correlated with damages; however, we do not believe that there is any logical relationship between the percentage of the labor force working for government agencies and housing damage. Rather, there are probably other underlying relationships not explored in this analysis that explain this correlation.

In Florida, each of the SoCI variables, except for the bonding SoCI, was positively associated with housing damage. These mixed results indicate that the SoCI is not a useful tool in predicting areas that are likely to experience greater levels of damage in a disaster. Future work should explore the relationship between social capital and disaster impacts in more detail. As discussed above, we modified some of the indicators that comprise the SoCI for this study. In their paper, Kyne and Aldrich explain the theory behind each of the indicators included the SoCI. Our modifications were not based on differences in theory; rather, we modified the indicators to align with the theories presented in the original paper more closely. Therefore, we do not believe that our variable modifications confound these results.

None of the indices assessed in this study were statistically significant in the recovery analysis. Because there are no publicly available datasets for tracking the disaster recovery process, resilience indices such as the SVI and SoCI have typically been developed and validated using only disaster impact data. While the variables selected for these indices are justified based on reviews of the literature and the underlying theory, empirical validation is necessary to ensure the resulting indices are useful 
for emergency managers and other practitioners who may rely on them. The results of this study suggest that the SVI and SoCI may need further development to ensure that they are applicable in resilience assessments focused on the recovery phase of the disaster cycle. Limitations of the methods used in this study may have also affected these results and are discussed below.

\section{Limitations and Future Work}

The impact assessment portion of this study looked at real property losses for owner-occupied households. It is possible that excluding renters and personal property losses from this study may have affected the results of the SVI assessment. Low-income households are more likely to rent rather than own their home. Therefore, the data used to calculate housing damage may have been biased toward higher-income households. Additionally, SVI theme 4 includes measures of multi-unit housing, which are often renter-occupied, and mobile homes, which are often categorized as personal property instead of real property. These categorizations may have also further biased the analysis towards less vulnerable populations.

There are also limitations to the recovery analysis presented in this study. We relied on historic aerial imagery from Google Earth to count blue roofs and develop our measures of housing recovery. The primary limitation is that focusing only on blue roofs does not consider other types of damage that may be more difficult to detect without more advanced image analysis techniques. There were also technical limitations to this method. The availability of historic imagery varies greatly depending on location, and some areas may be obscured by cloud cover. For these reasons, we were not always able to view the census tracts in the sample on the exact dates we chose for the study (20 March 2018 and 20 September 2019), and in some cases, we had to rely on imagery up to three months before or after the target date. Additionally, because Google Earth provides high-resolution imagery from a variety of sources captured from a variety of instruments, there are differences in the resolution and color spectrum in the imagery analyzed for this study, which increased the possibility of blue roof counting errors. To address these issues, future work should include funding to purchase aerial imagery of the study area with more consistent availability and visibility. More robust methodologies for recovery tracking in aerial imagery should also be incorporated.

As mentioned above, the mixed results from the analyses of the SoCI and SoCI sub-indices point to a need for more work in developing appropriate indicators of social capital. The variables in the SoCI, and other social capital indices that came before, have been selected based on theory and assumptions about how people form connections with one another. They have been validated with indicators that represent the expected outcomes of different levels of social capital. Future work should incorporate social network analysis, a standard method for studying social networks, to directly study the relationship between potential social capital indicators, and the structure of social networks in communities.

\section{Conclusions}

The purpose of this study was to evaluate the effectiveness of the SVI and SoCI as tools for resilience assessment. Using data from Florida and Puerto Rico from the 2017 hurricane season, we assessed each index's ability to explain variation in levels of housing damage within the study area. We also assessed the ability of the indices to explain variation in levels of housing recovery in a sample of 36 census tracts two years after the landfall of Hurricane Maria.

Our results show that the SVI is an effective tool to explain variation in disaster impacts. We also show, by assessing the individual theme indices of the SVI, that the socioeconomic theme of the SVI is more effective at predicting variation in housing damage than any other theme, including the overall SVI. The impact assessment showed mixed results for the SoCI, and we believe that more work to validate the SoCI as a tool for resilience assessment should be done before it is adopted as a tool by practitioners. Neither the SVI, the SoCI, nor any of the sub-indices, were significant in the recovery assessment portion of this study. There were several limitations with this method as described above, 
which should be addressed in future work. However, these results highlight certain usefulness and limitations to these indices of which practitioners who rely on them should be aware.

Author Contributions: Conceptualization, S.R. and K.K.; methodology, S.R. and K.K.; software, S.R.; validation, S.R. and K.K.; formal analysis, S.R. and K.K.; investigation, S.R.; resources S.R. and K.K.; data curation, S.R.; writing-original draft preparation, S.R. and K.K.; writing - review and editing, S.R. and K.K.; visualization, S.R., and K.K.; supervision, K.K.; project administration, S.R. and K.K.; funding acquisition, K.K. All authors have read and agreed to the published version of the manuscript.

Funding: This research received no external funding.

Acknowledgments: We thank Dean Kyne and Daniel Aldrich for their helpful discussion regarding the Social Capital Index.

Conflicts of Interest: The authors declare no conflict of interest.

\section{Appendix A}

Table A1. Social Vulnerability Index variables.

\begin{tabular}{|c|c|}
\hline Social Vulnerability Theme & SVI Variable \\
\hline Socioeconomic Status & $\begin{array}{c}\text { Percentage of persons below poverty line } \\
\text { Percentage of civilians (age 16+) unemployed } \\
\text { Per capita income } \\
\text { Percentage of persons (age 25+) with no high school diploma }\end{array}$ \\
\hline Household Composition/Disability & $\begin{array}{c}\text { Percentage of population } 65 \text { years of age or older } \\
\text { Percentage of population } 17 \text { years of age or younger } \\
\text { Percentage of population more than } 5 \text { years old with a disability } \\
\text { Percentage male or female householder, no spouse present, with } \\
\text { children under } 18\end{array}$ \\
\hline Minority Status and Language & $\begin{array}{c}\text { Percentage minority } \\
\text { Percentage of population } 5 \text { years of age or older who speak English } \\
\text { less than "well" }\end{array}$ \\
\hline Housing and Transportation & $\begin{array}{c}\text { Percentage multi-unit housing } \\
\text { Percentage mobile homes } \\
\text { Crowding } \\
\text { Percentage no vehicle available } \\
\text { Percentage of population in group quarters }\end{array}$ \\
\hline
\end{tabular}

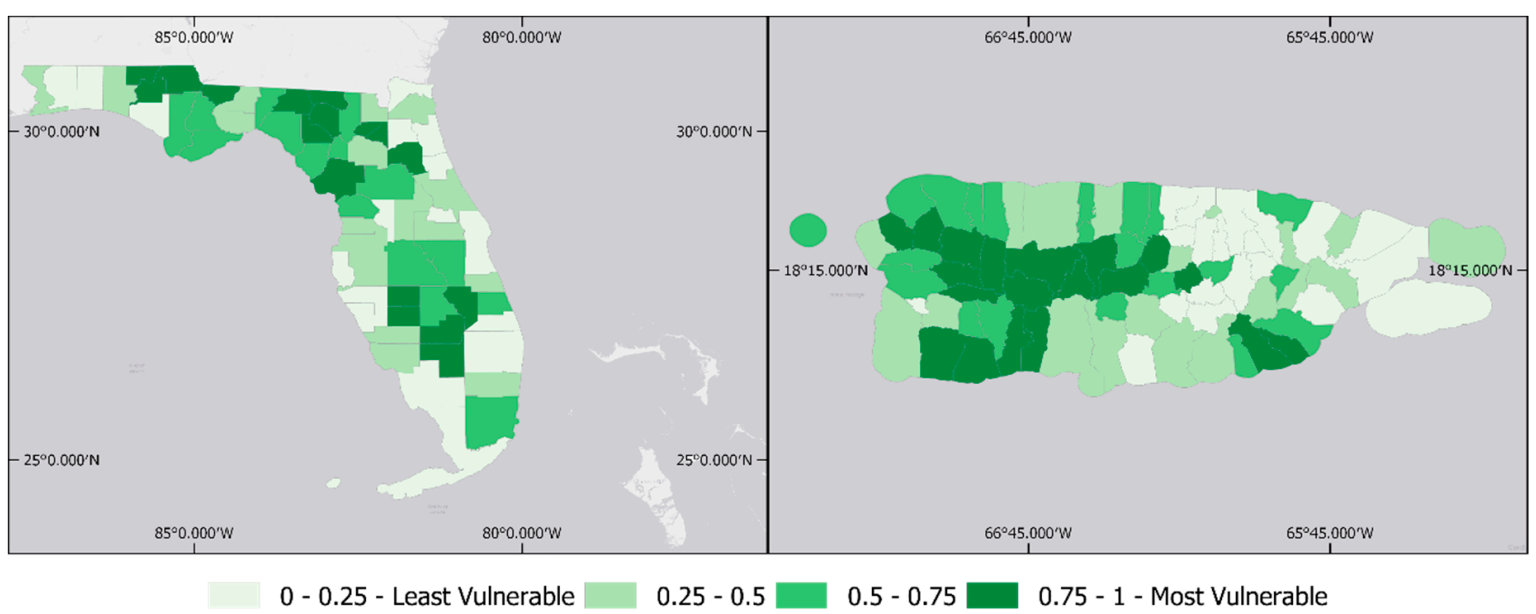

Figure A1. Distribution of social vulnerability based on socioeconomic status (SVI theme 1) in Florida (left) and Puerto Rico (right) colored by quartiles. 


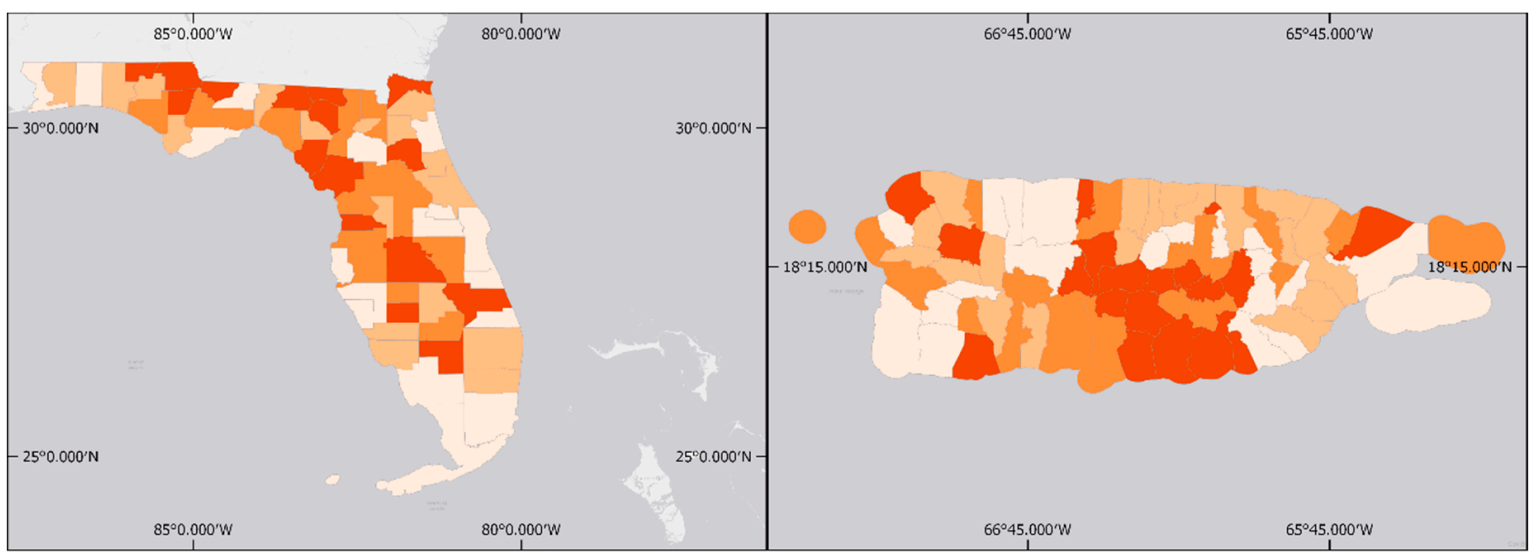

0 - 0.25 - Least Vulnerable

$0.25-0.5$

$0.5-0.75$

0.75 - 1 - Most Vulnerable

Figure A2. Distribution of social vulnerability based on household composition and disability (SVI theme 2) in Florida (left) and Puerto Rico (right) colored by quartiles.

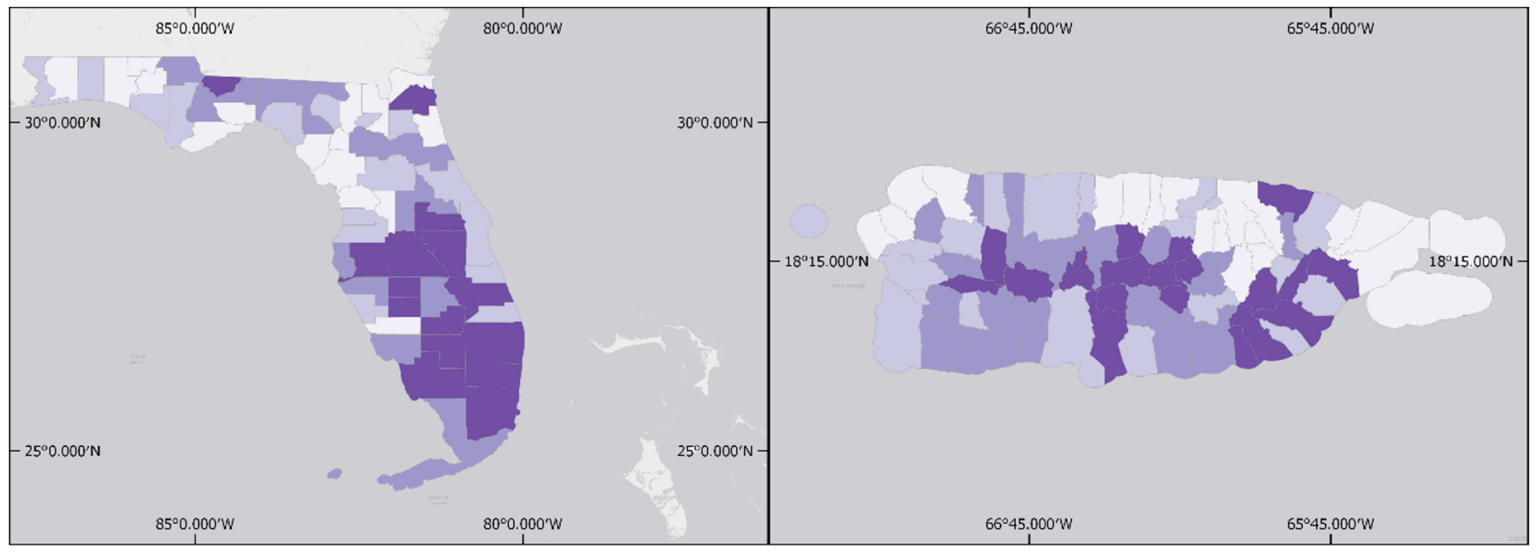

0 - 0.25 - Least Vulnerable

$0.25-0.5 \quad 0.5-0.75$

0.75 - 1 - Most Vulnerable

Figure A3. Distribution of social vulnerability based on minority status and language (SVI theme 3) in Florida (left) and Puerto Rico (right) colored by quartiles.

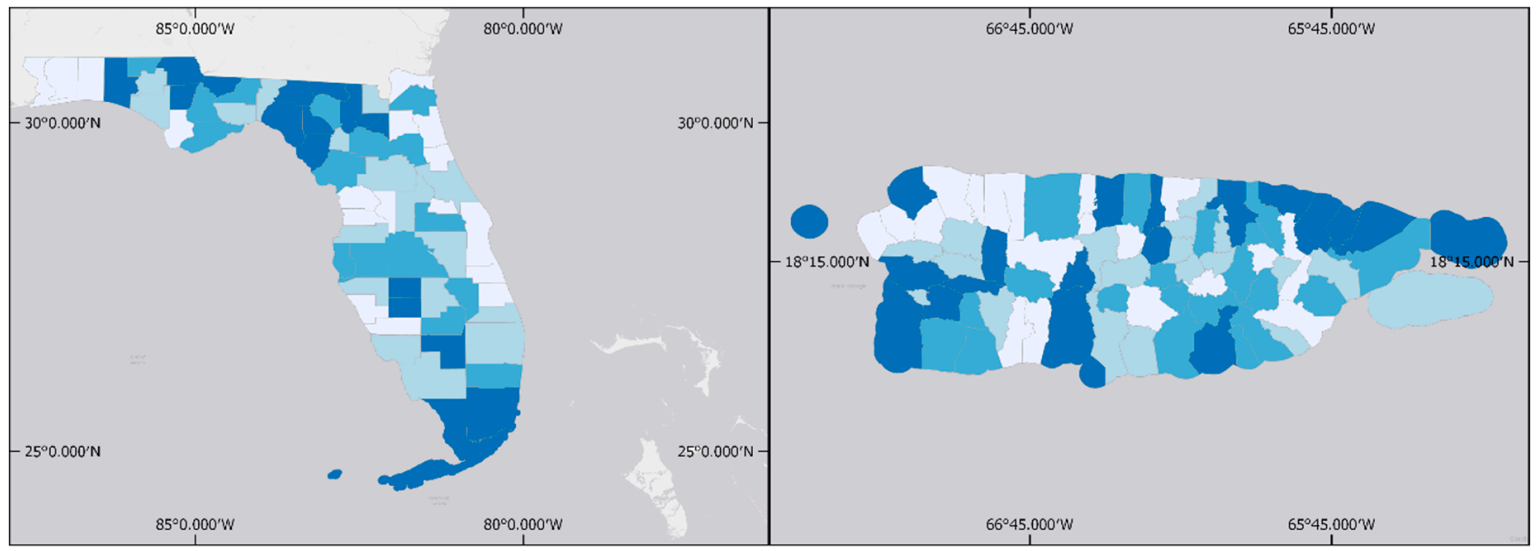

0 - 0.25 - Least Vulnerable

$0.25-0.5$

$0.5-0.75$

0.75 - 1 Most Vulnerable

Figure A4. Distribution of social vulnerability based on housing and transportation (SVI theme 1) in Florida (left) and Puerto Rico (right) colored by quartiles. 
Table A2. Social Capital Index variables.

\begin{tabular}{|c|c|}
\hline Social Capital Type & SoCI Variable \\
\hline \multirow{9}{*}{ Bonding } & Race similarity \\
\hline & Ethnicity similarity \\
\hline & Education equality ${ }^{1}$ \\
\hline & Income equality \\
\hline & Employment equality ${ }^{1}$ \\
\hline & Gender income equality ${ }^{1}$ \\
\hline & Language competency \\
\hline & Communication capacity \\
\hline & Non-elder population \\
\hline \multirow[t]{5}{*}{ Bridging } & Religious organizations \\
\hline & Civic organizations \\
\hline & Charitable ties ${ }^{1}$ \\
\hline & Fraternal ties ${ }^{2}$ \\
\hline & Union ties ${ }^{1}$ \\
\hline \multirow[t]{5}{*}{ Linking } & Political linkage (voting-age population) \\
\hline & Local government linkage \\
\hline & State government linkage \\
\hline & Federal government linkage \\
\hline & Political activities 1 \\
\hline
\end{tabular}

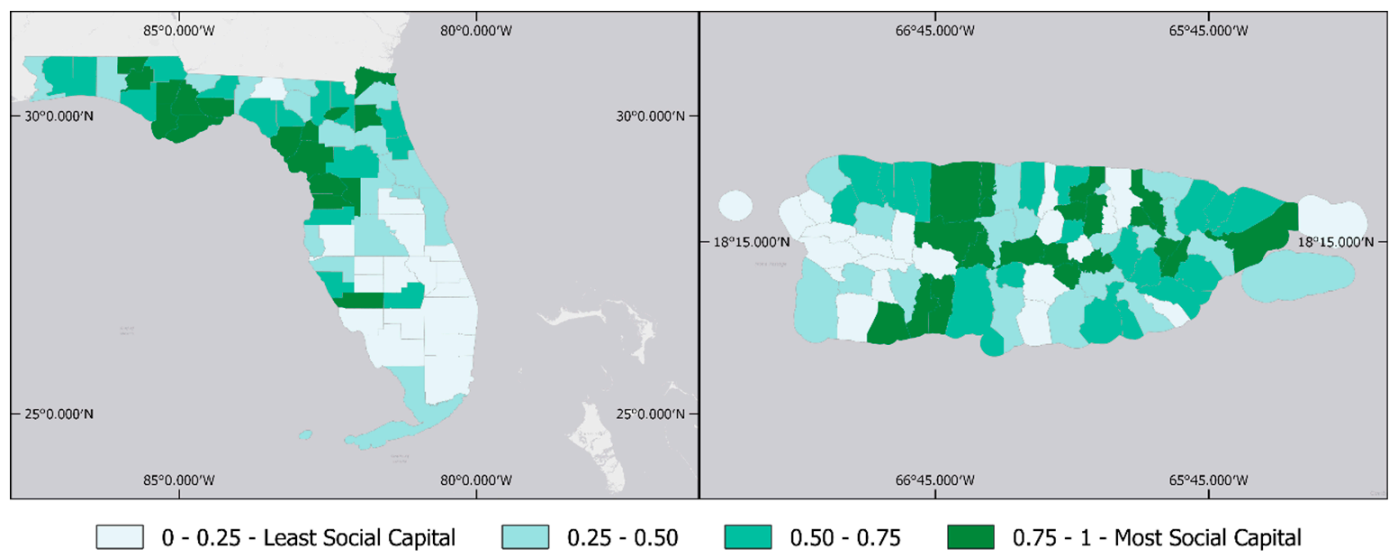

Figure A5. Distribution of bonding social capital in Florida (left) and Puerto Rico (right) colored by quartiles.

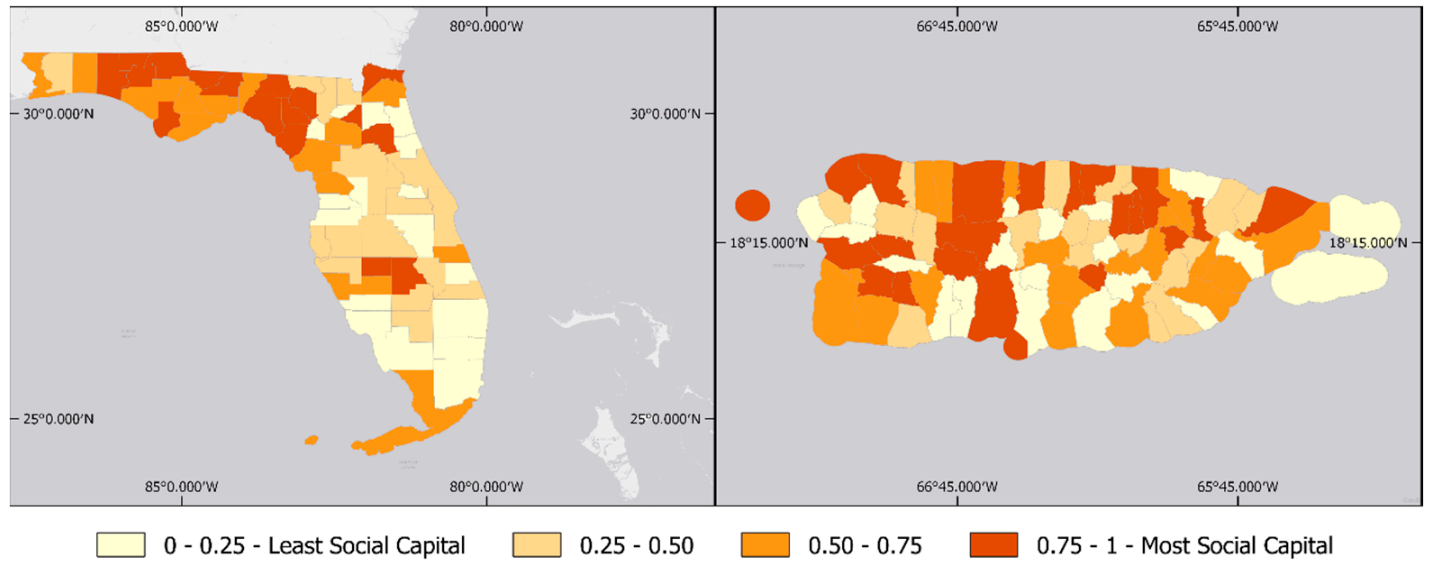

Figure A6. Distribution of bridging social capital in Florida (left) and Puerto Rico (right) colored by quartiles. 


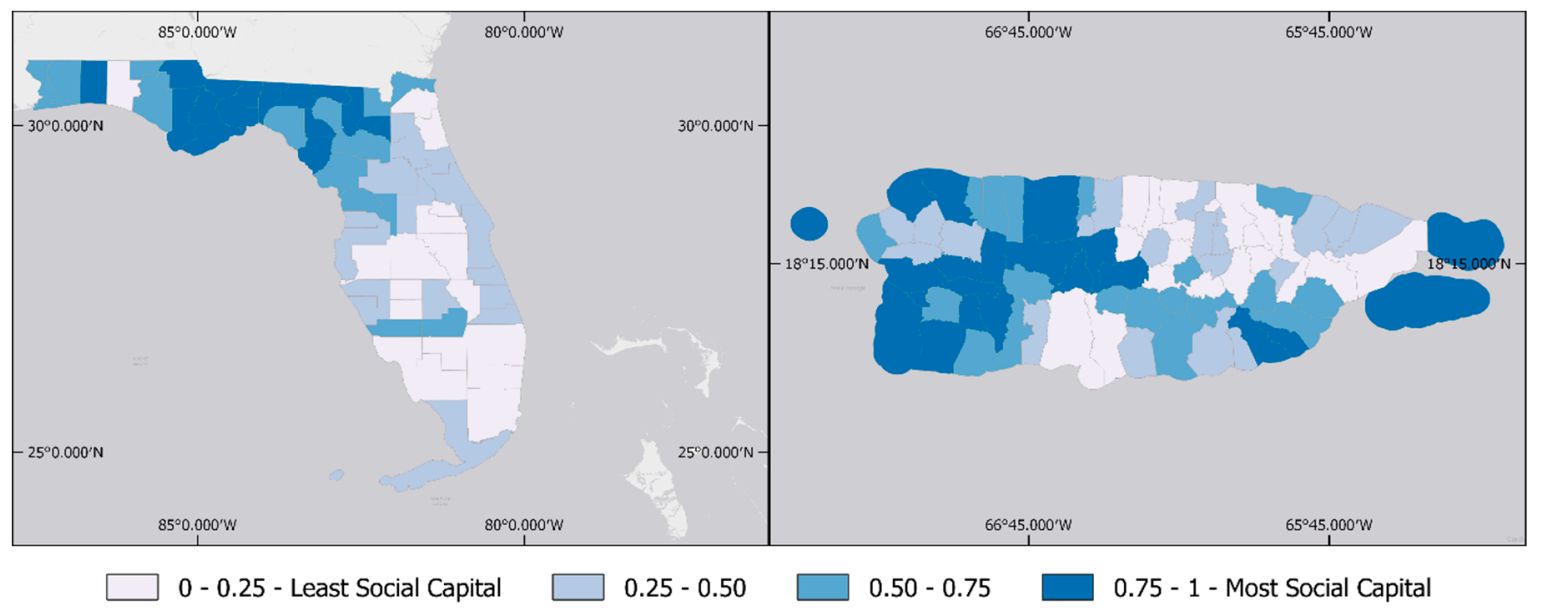

Figure A7. Distribution of linking social capital in Florida (left) and Puerto Rico (right) colored by quartiles.

\section{Appendix B}

We calculated the education Gini coefficient for this study using the first formula for calculating the education Gini from Thomas et al. [25] shown in Equation (A1).

$$
E_{L}=\left(\frac{1}{\mu}\right) \sum_{i=2}^{n} \sum_{j}^{i-1} p_{i}\left|y_{i}-y_{j}\right| p_{j}
$$

where,

$E_{L}$ is the education Gini based on educational attainment distribution,

$\mu$ is the average years of schooling for the concerned population,

$p_{i}$ and $p_{j}$ stand for the proportions of population with certain levels of schooling,

$y_{i}$ and $y_{j}$ are the years of schooling at different educational attainment levels,

$n$ is the number of levels/categories in attainment data, $n=7$ in this paper (less than 9th grade, 9th to 12th grade (no diploma), high school graduate (including equivalency), some college (no degree), associate's degree, bachelor's degree, graduate or professional degree).

Equation (A1) is expanded to get the detailed summation process for the education Gini as shown in Equation (A2).

$$
\begin{gathered}
E_{L}=\left(\frac{1}{\mu}\right)\left[p_{2}\left(y_{2}-y_{1}\right) p_{1}+p_{3}\left(y_{3}-y_{1}\right) p_{1}+p_{3}\left(y_{3}-y_{2}\right) p_{2}+\cdots+p_{7}\left(y_{7}-y_{1}\right) p_{1}\right. \\
+p_{7}\left(y_{7}-y_{2}\right) p_{2}+p_{7}\left(y_{7}-y_{3}\right) p_{3}+p_{7}\left(y_{7}-y_{4}\right) p_{4}+p_{7}\left(y_{7}-y_{5}\right) p_{5} \\
\left.+p_{7}\left(y_{7}-y_{6}\right) p_{6}\right]
\end{gathered}
$$

where,

$p_{1}$ is the portion of population with less than 9th grade education,

$p_{2}$ is the portion of population with 9 th to 12 th grade education,

......

$p_{7}$ is the portion of population with a graduate or professional degree.

$y_{1}$ is the years of schooling for an individual with less than 9th grade education, $y_{1}=4.5$,

$y_{2}$ is the years of schooling for an individual with 9 th to 12 th grade education, $y_{2}=10$,

$y_{3}$ is the years of schooling for an individual with high school education, $y_{3}=12$,

$y_{4}$ is the years of schooling for an individual with some college education, $y_{4}=13$,

$y_{5}$ is the years of schooling for an individual with an associate's degree, $y_{5}=14$, 
$y_{6}$ is the years of schooling for an individual a bachelor's degree, $y_{6}=16$,

$y_{7}$ is the years of schooling for an individual with a graduate or professional degree, $y_{7}=18$.

For educational attainment groups that represent partial attainment of a schooling cycle (less than 9th grade, 9th to 12th grade (no diploma), and some college (no degree)), the years of schooling for the group were assumed to be the midpoint between the previous and next schooling cycles.

\section{References}

1. CRED. Natural Disasters 2018; Centre for Research on the Epidemiology of Disasters: Brussels, Belgium, 2019.

2. IPCC. Summary for Policymakers. In Climate Change 2014: Impacts, Adaptation, and Vulnerability. Part A: Global and Sectoral Aspects. Contribution of Working Group II to the Fifth Assessment Report of the Intergovernmental Panel on Climate Change; Field, C.B., Barros, V.R., Dokken, D.J., Mach, K.J., Mastrandrea, M.D., Bilir, T.E., Chatterjee, M., Ebi, K.L., Estrada, Y.O., Genova, R.C., et al., Eds.; Cambridge University Press: Cambridge, UK; New York, NY, USA, 2014; pp. 1-32.

3. Knutson, T.; Camargo, S.J.; Chan, J.C.L.; Emanuel, K.; Ho, C.-H.; Kossin, J.; Mohapatra, M.; Satoh, M.; Sugi, M.; Walsh, K.; et al. Tropical Cyclones and Climate Change Assessment: Part II: Projected Response to Anthropogenic Warming. Bull. Am. Meteorol. Soc. 2020, 101, E303-E322. [CrossRef]

4. Agency for Toxic Substances and Disease Registry. CDC's Social Vulnerability Index (SVI); Agency for Toxic Substances and Disease Registry: Atlanta, GA, USA, 2018.

5. Flanagan, B.E.; Hallisey, E.J.; Adams, E.; Lavery, A. Measuring Community Vulnerability to Natural and Anthropogenic Hazards: The Centers for Disease Control and Prevention's Social Vulnerability Index. J. Environ. Health 2018, 80, 34-36. [PubMed]

6. Kyne, D.; Aldrich, D.P. Capturing Bonding, Bridging, and Linking Social Capital through Publicly Available Data. Risk Hazards Crisis Public Policy 2020, 11, 61-86. [CrossRef]

7. Cutter, S.L. Vulnerability to environmental hazards. Prog. Hum. Geogr. 1996, 20, 529-539. [CrossRef]

8. White, G.F. Assessment of Research on Natural Hazards; The MIT Press environmental studies series; MIT Press: Cambridge, MA, USA, 1975; ISBN 0-262-08083-4.

9. Flanagan, B.E.; Gregory, E.W.; Hallisey, E.J.; Heitgerd, J.L.; Lewis, B. A Social Vulnerability Index for Disaster Management. J. Homel. Secur. Emerg. Manag. 2011, 8. [CrossRef]

10. Morrow, B.H. Identifying and Mapping Community Vulnerability. Disasters 1999, 23, 1-18. [CrossRef] [PubMed]

11. Cutter, S.L.; Boruff, B.J.; Shirley, W.L. Social Vulnerability to Environmental Hazards. Soc. Sci. Q. 2003, 84, 242-261. [CrossRef]

12. Federal Emergency Management Agency. The Disaster Declaration Process; Federal Emergency Management Agency: Washington, DC, USA, 2020.

13. Davies, G. Pre-Modern Disaster Politics: Combating Catastrophe in the 1950s. Publius J. Fed. 2017, 47, 260-281. [CrossRef]

14. Sherrieb, K.; Norris, F.H.; Galea, S. Measuring Capacities for Community Resilience. Soc. Indic. Res. 2010, 99, 227-247. [CrossRef]

15. Aldrich, D.P. Building Resilience: Social Capital in Post-Disaster Recovery; University of Chicago Press: Chicago, IL, USA, 2012; ISBN 0-226-01287-5.

16. Nakagawa, Y.; Shaw, R. Social Capital: A Missing Link to Disaster Recovery. Int. J. Mass Emergencies Disasters 2004, 22, 5-34.

17. Norris, F.H.; Stevens, S.P.; Pfefferbaum, B.; Wyche, K.F.; Pfefferbaum, R.L. Community Resilience as a Metaphor, Theory, Set of Capacities, and Strategy for Disaster Readiness. Am. J. Community Psychol. 2008, 41, 127-150. [CrossRef] [PubMed]

18. Putnam, R.D. Bowling alone: The Collapse and Revival of American Community; Simon \& Schuster: New York, NY, USA, 2000; ISBN 978-0-684-83283-8.

19. Aldrich, D.P.; Meyer, M.A. Social Capital and Community Resilience. Am. Behav. Sci. 2015, 59, $254-269$. [CrossRef]

20. MacGillivray, B.H. Beyond social capital: The norms, belief systems, and agency embedded in social networks shape resilience to climatic and geophysical hazards. Environ. Sci. Policy 2018, 89, 116-125. [CrossRef] 
21. Rupasingha, A.; Goetz, S.J.; Freshwater, D. The production of social capital in US counties. J. Socio-Econ. 2006, 35, 83-101. [CrossRef]

22. Cangialosi, J.P.; Latto, A.S.; Berg, R. Tropical Cyclone Report: Hurricane Irma; National Hurricane Center: Miami, FL, USA, 2018.

23. NOAA. Costliest U.S. Tropical Cyclones; NOAA, National Hurricane Center: Miami, FL, USA, 2020.

24. Pasch, R.J.; Penny, A.B.; Berg, R. Tropical Cyclone Report: Hurricane Maria; National Hurricane Center: Miami, FL, USA, 2019.

25. Thomas, V.; Wang, Y.; Fan, X. Measuring Education Inequality-Gini Coefficients of Education; World Bank: Washington, DC, USA, 2000.

26. U.S. Census Bureau. American Community Survey, 2016 American Community Survey 5-year Estimates; U.S. Census Bureau: Suitland, MD, USA, 2017.

27. ARA. ARA Hurricane Irma Wind Maps v12; ARA: Albuquerque, NM, USA, 2017.

28. ARA. ARA Hurricane Maria Wind Maps v17; ARA: Albuquerque, NM, USA, 2017.

29. Vugrin, E.D.; Warren, D.E.; Ehlen, M.A.; Camphouse, R.C. A Framework for Assessing the Resilience of Infrastructure and Economic Systems. In Sustainable and Resilient Critical Infrastructure Systems; Gopalakrishnan, K., Peeta, S., Eds.; Springer: Berlin/Heidelberg, Germany, 2010; pp. 77-116. ISBN 978-3-642-11404-5.

30. Brown, D.; Saito, K.; Spence, R.; Chenvidyakarn, T.; Adams, B.; Mcmillan, A.; Ltd, I.; Platt, S. Indicators for Measuring, Monitoring and Evaluating Post-Disaster Recovery. In Proceedings of the 6th International Workshop on Remote Sensing for Disaster Applications, Pavia, Italy, 11-12 September 2008; p. 8.

31. Brown, D.; Platt, S.; Bevington, J. Disaster Recovery Indicators; CURBE, Cambride University Centre for Risk in the Built Environment: Cambridge, UK, 2010; p. 134.

32. Archer, R.S. Measuring and Monitoring Long Term Disaster Recovery Using Remote Sensing: A Case Study of Post Katrina New Orleans. In Proceedings of the AutoCarto 2012, Columbus, OH, USA, 16-18 September 2012.

33. USACE. Corps Installs Last Blue Roof in Puerto Rico. Available online: https://www.army.mil/article/202599/ corps_installs_last_blue_roof_in_puerto_rico (accessed on 29 April 2019).

34. Florido, A. Two Years After Hurricane Maria, Blue Tarps Are Symbol of Island's Slow Recovery; National Public Radio: Washington, DC, USA, 2019.

(C) 2020 by the authors. Licensee MDPI, Basel, Switzerland. This article is an open access article distributed under the terms and conditions of the Creative Commons Attribution (CC BY) license (http://creativecommons.org/licenses/by/4.0/). 